\title{
Joint flood control operation of Upper Yangtze River based on dynamic weight of system safety degree
}

\author{
Zhenghe $\mathrm{Li}^{1}$, Ling Kang ${ }^{1, *}$, Liwei Zhou and Jie $\mathrm{Hu}^{1}$ \\ ${ }^{1}$ Huazhong University of S\&T, School of Hydropower\& Information Engineering, 430070 Wuhan, PR China
}

\begin{abstract}
At flood season, reservoir can guarantee the power generation and other benefit only under the premise of ensuring its own safety and the safety of middle and lower reaches of river basin. For maximizing the comprehensive benefits of each reservoir's function, it is necessary to study the scientific operation strategy of single reservoir and reservoir groups. Joint flood control operation of reservoir groups can achieve the task of flood control to maximum extent and balance the water demands of each reservoir's function. Aimed at five controlling reservoirs in the upper Yangtze river, this paper put forward the static and dynamic weight calculation methods of the system safety degree, and developed a joint flood control operation model of reservoir groups with the goal of minimizing downstream flood volume and maximizing system safety degree of reservoir groups. We studied the flood control effect of two operation strategies, the static weight piecewise linear strategy and the dynamic weight piecewise linear strategy, on downstream flood control station under 100-year design flood condition in 1998. The results showed that the dynamic weight piecewise linear strategy can give full play to the role of each controlling reservoir in flood control operation at flood season.
\end{abstract}

\section{Introduction}

\subsection{Research Background}

Reservoirs have flood control, hydropower generation, water supply, shipping, ecological and other functions. Several reservoirs in Upper Yangtze River of China have been built to better perform the river basin water resource management, and these reservoirs have formed different sizes of parallel and mixed reservoir groups. In flood season, reservoirs must operate at flood control level and release the flood control storage capacity for the prospective flood. [1] Reservoir should operate at certain water level to maintain the function of hydropower generation and ecology. [2] Hence, it is necessary to study the scientific operation strategy of single reservoir and reservoir groups. [3] For example, [4] [5] proposed an explicit risk consideration based methodology to determine the reservoir operation policy which was found to be satisfactory with the performance of operation policy. To emphasis on flood control and ecology, [6] introduced a new dynamic operating policy for flood control operation. [7] proposed an improved equal proportion flood retention strategy, which had reservoirs flood storage capacity used adequately, and resulted in an obvious reduction of excess flood volume in downstream flood control section. Focusing on the multi-objective problem of joint flood control operation for cascade reservoirs in Upper Yangtze River, [8] established a multi-objective optimization model which was solved by the proposed multi-objective particle swarm algorithm. And [9] had transformed short-term flood forecast into flood control operation model, this research achievement provided scientific basis for reservoir dynamically choosing flood control water level. The previous research on strategies study, model solutions and multi-objective optimization had adequate application prospects and solving strategies. But for quantitatively characterized the safety degree of reservoirs and considered flood forecast in flood control operation, these researches may not be conclusive. To make the research result more valuable, this paper adopted the system safety degree of the reservoir groups, and proposed the piecewise linear safety degree of single reservoir [10]. Furthermore, we put forward the static and dynamic weight calculation methods of the system safety degree, and developed a joint flood control operation model of reservoir groups with the goal of minimizing downstream flood volume and maximizing system safety degree of reservoir groups.

\subsection{Research Area}

Yangtze River, a total length of $6300 \mathrm{~km}$, drainage area of 1.8 million $\mathrm{km}^{2}$, is the longest river in China. [11] Xiluodu and Xiangjiaba reservoir in Upper Yangtze River has steady reservoir inflow [12], and were important part of flood control system of Yangtze River basin [13]. Zipingpu reservoir, which located at mainstream of Min River was mainly responsible for the flood control of Jinma River, has incomplete annual regulation capacity. Pubugou and Tingzikou reservoir,

\footnotetext{
* Corresponding author: $\underline{\mathrm{kling} @ \text { hust.edu.cn }}$
} 
which located at Dadu River and Jialing River respectively, both have seasonal regulation capacity [14]. The sketchy location of each reservoirs was showed in Fig.1. In this paper, five controlling reservoirs introduced above were selected as flood control operation object and Cuntan hydrology station near Chongqing City was selected as flood control section, and we studied the joint optimal flood control operation of Upper Yangtze River to guarantee the flood control safety of Chongqing City.

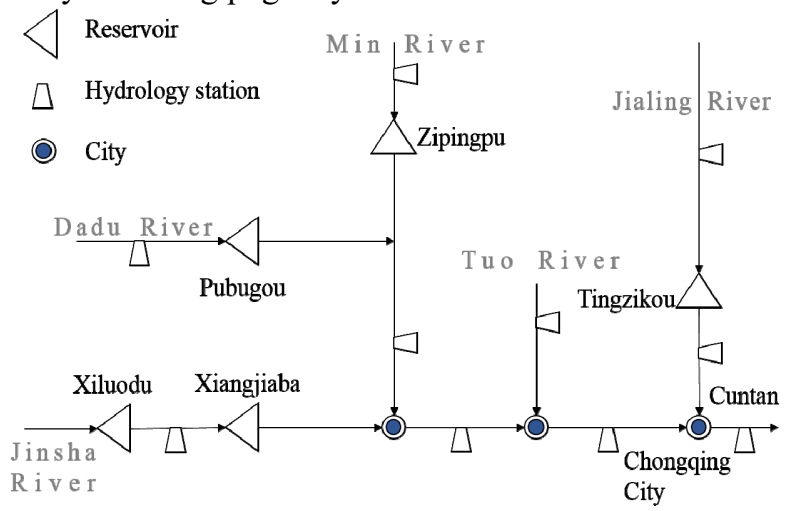

Fig.1. The sketchy location of each controlling reservoir in Upper Yangtze Rive

\section{Flood control strategies}

To quantitatively characterize the safety degree of reservoirs and consider flood forecast in flood control operation, the concept of system safety degree and the calculation method of the dynamic weight of system safety degree were proposed.

\subsection{Safety degree}

Safety degree refers to an index that indicates the safety degree of reservoir in the process of optimal flood control operation. Linear safety degree assumed that the relationship between the used Design Flood Storage Capacity (DFSC) and safety degree was linear, the definition written as:

$$
S_{r e s}^{t}=1-V_{u s e}^{t} / V_{\text {flo }}
$$

Even the linear safety degree was simplified, the actual situation of flood control operation was far away from simple. Furthermore, the piecewise linear safety degree outperformed the linear safety degree. Hence, we adopted the piecewise linear safety degree only. Piecewise linear safety degree assumed that the relationship between the used DFSC and safety degree was piecewise linear, the definition written as:

$$
S_{r e s}^{t}= \begin{cases}-0.2 V_{u s e}^{t} / V_{f l o}+1 & 0 \leq V_{u s e}^{t} / V_{f l o}<0.5 \\ -V_{u s e}^{t} / V_{f l o}+1.4 & 0.5 \leq V_{u s e}^{t} / V_{f l o}<0.9 \\ -5 V_{u s e}^{t} / V_{f l o}+5 & 0.9 \leq V_{u s e}^{t} / V_{f l o} \leq 1\end{cases}
$$

Where $S_{\text {res }}^{t}=$ the safety degree of reservoir at time $t$; $V_{u s e}^{t}=$ the used DFSC at time $t ; V_{\text {flo }}=$ the DFSC of reservoir. For a reservoir groups which have number reservoirs, the system safety degree at time can be written as:

$$
S_{s y s}^{t}=\sum_{i=1}^{n} w_{i} S_{r e s, i}^{t}
$$

Where $S_{s y s}^{t}=$ the system safety degree of reservoir groups at time $t ; w_{i}=$ the weight of safety degree of reservoir $i ; S_{\text {res }, i}^{t}=$ the safety degree of reservoir $i$ at time $t$.

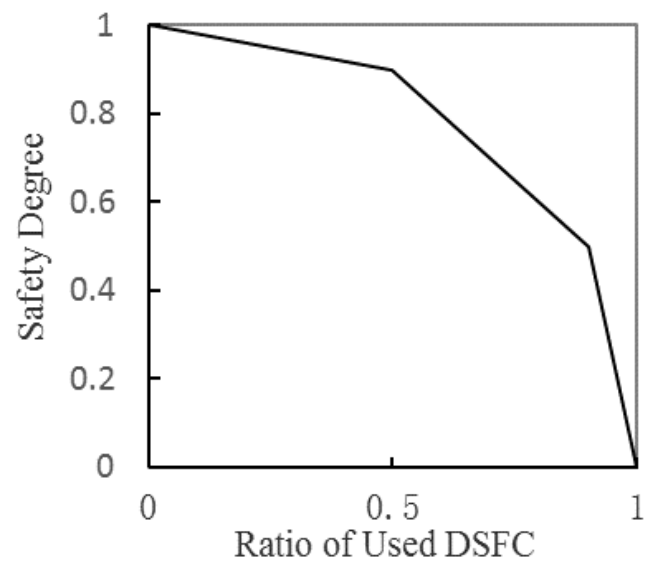

Fig.2. Piecewise linear safety degree

\subsection{Objective function}

Combined with the system safety degree of flood control system proposed before, the objective function of the optimal flood control operation model can be written as:

$\min f_{1}=\min W=\min \left\{\sum_{i=1}^{m} \sum_{t=1}^{T} \max \left(Q_{i}^{t}-Q_{i}^{\lim }, 0\right) \Delta t\right\}$

$\max f_{2}=\max S_{s y s}=\max \frac{1}{T} \sum_{t=1}^{T} \sum_{i=1}^{n} w_{i} S_{r e s, i}^{t}$

$\min f_{\text {total }}=\lambda_{W}\left(W / W_{\max }\right)+\lambda_{S}\left(-S_{s y s}\right)$

Where $W=$ the downstream flood volume of flood control section during flood control operation period; $Q_{i}^{t}=$ the average transit flood volume of flood control section $i$ at time $t ; Q_{i}^{\lim }=$ the maximum flood volume that flood control section $i$ could bear; $m=$ total number of flood control sections; $T=$ total number of flood control operation periods; $\Delta t=$ unit time interval; $\lambda_{W}=$ the weight of $f_{1}$ in the total objective function; $\lambda_{S}=$ the weight of $f_{2}$ in the total objective 
function; $W_{\max }=$ sum of downstream flood volume of all flood control section. We set $\lambda_{W}=0.7, \lambda_{S}=0.3$ in this study.

\subsection{Basic constrains}

\subsubsection{Water balance equation of reservoirs}

$V_{i}^{t+1}-V_{i}^{t}=\left(I_{i}^{t}+I_{\mathrm{sec}, i}^{t}+I_{r e s, i}^{t}-q_{i}^{t}\right) \Delta t$

Where $V_{i}^{t+1}=$ the initial storage capacity of reservoir $i$ at period $t+1 ; V_{i}^{t}=$ the initial storage capacity of reservoir $i$ at period $t ; I_{i}^{t}=$ the average inflow of reservoir $i$ at period $t ; I_{\mathrm{sec}, i}^{t}=$ the average local inflow of reservoir $i$ at period $t ; I_{\text {res }, i}^{t}=$ the average precipitation inflow of reservoir $i$ at period $t$; $q_{i}^{t}=$ the average outflow of reservoir $i$ at period $t ; \Delta t$ $=$ time interval of period $t$.

\subsubsection{Storage capacity limitation of reservoir}

$V_{i}^{\min } \leq V_{i}^{t} \leq V_{i}^{\max }$

Where $V_{i}^{\text {min }}=$ the flood water level storage of reservoir $i ; V_{i}^{\max }=$ the high water level storage for flood control of reservoir $i$; the value of $V_{i}^{\max }-V_{i}^{\min }$ approximately equals to the DFSC of reservoir $i$ commonly.

\subsubsection{Safety of flood control section}

$\sum_{k=1}^{n} q_{k}^{t-\tau(k)}+\sum_{j=1}^{m} I_{t r i, j}^{t-\tau(j)} \leq Q_{i}^{\lim }$

Where $Q_{i}^{\text {lim }}=$ the limitation flood volume of flood control section.

\subsection{Model solution}

The model established in this paper was a multidimensional and multi-stage optimization problem. We proposed Particle Swarm Optimization (PSO) algorithm for model solution. The programming sequence was showed in Fig.3.

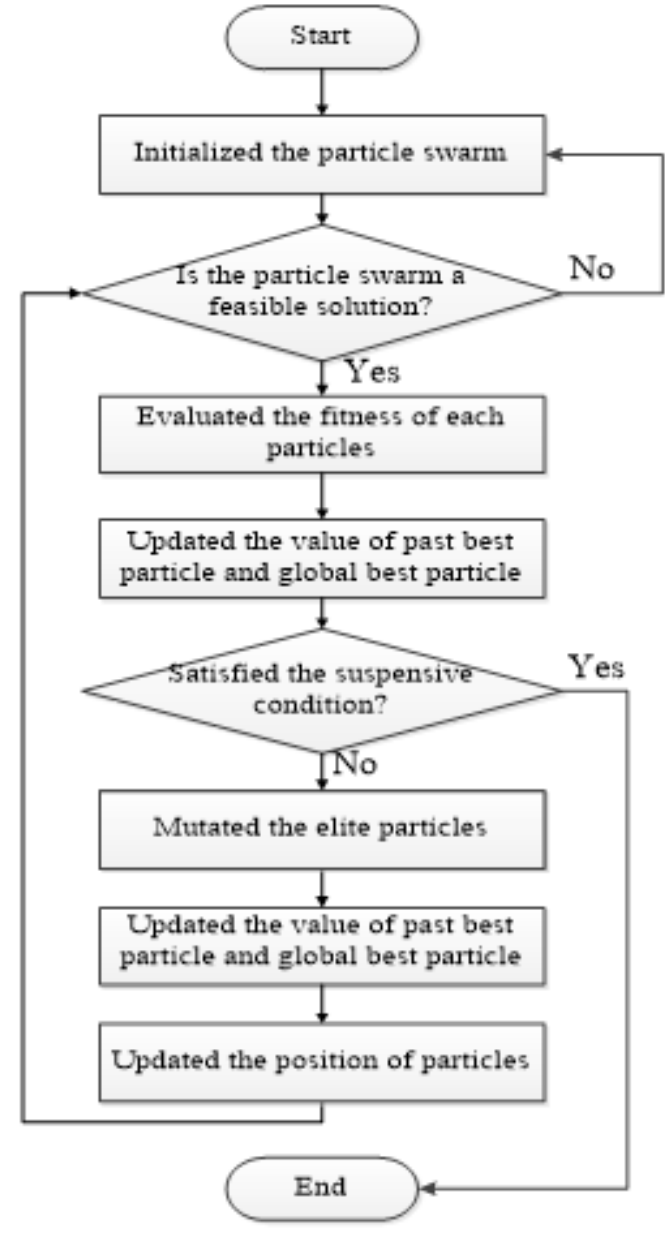

Fig.3. The programming sequence of model

\subsection{The weight calculation method of system safety degree}

Weight of reservoir safety degree refers to the importance of the reservoir in reservoir groups of flood control operation. The greater value the weight was, the more influence it would exert in the flood control operation.

\subsubsection{Static weight of safety degree}

The weight of safety degree remains the same during the operation period. The mathematic expression of this calculation method can be written as:

$w_{i}=\frac{A_{i} Q_{\text {mean }, i}}{V_{\text {flood }, i} \tau(i)}$

Where $w_{i}=$ the safety degree of reservoir $i ; A_{i}=$ the catchment area above the dam site of reservoir $i$, $10^{4} * \mathrm{~km}^{2} ; Q_{\text {mean }, i}=$ the mean annual discharge of reservoir $i, \mathrm{~m}^{3} / \mathrm{s} ; V_{\text {flood, } i}=$ the designed flood storage capacity of reservoir $i, 10^{8 *} \mathrm{~m}^{3} ; \tau(i)=$ the time of flood routing between reservoir $i$ and Cuntan station, $h$. 


\subsubsection{Dynamic weight of safety degree}

The weight of safety degree fluctuates with hydrology forecast in the following operation period. It mathematic expression can be written as:

$$
w_{i, t}=\frac{Q_{i, t}}{V_{\text {flood }, i} \tau(i)}
$$

Where $w_{i, t}=$ the safety degree of reservoir $i$ at period $t ; Q_{i, t}=$ the hydrology forecast of reservoir $i$ inflow during period $t$ to the end of operation. The dynamic weight of each controlling reservoir under the hydrology forecast data in 1998 was showed in Fig.4.

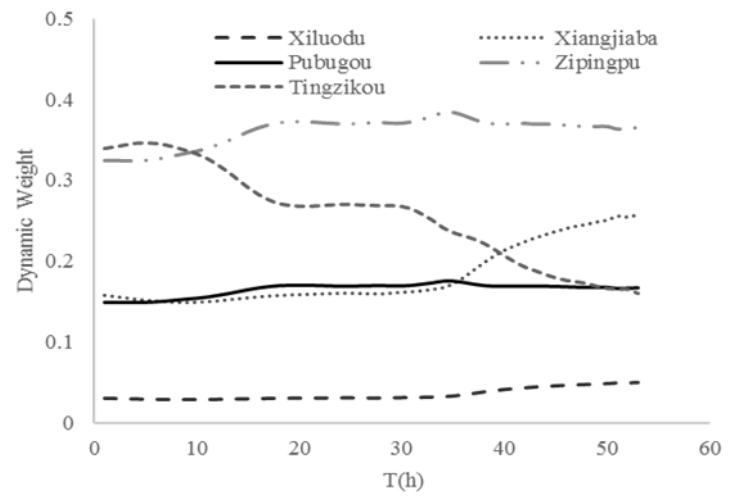

Fig.4. The dynamic weight of each controlling reservoir

\section{Case study}

Aimed at minimizing the excess flood volume of flood control section during the operation period, this paper adopted two operation strategies, the static weight piecewise linear strategy and the dynamic weight piecewise linear strategy, to research the flood control problem of reservoir groups in Upper Yangtze River under 100-year design flood condition in 1998. And we adopted PSO algorithm for model solution of flood control operation problems. [7] The calculation result of two strategies demonstrated the flood process of Cuntan station and maximum used percentage of DFSC of each reservoir which also showed as minimum safety degree.

The Tab.1. showed the main calculation result of these two strategies. Under the conduction of dynamic weight piecewise linear strategy, Xiluodu and Xiangjiaba reservoir only slightly raised its usage of DFSC so that the maximum usage of DFSC and accumulated usage of DFSC of other three reservoirs have declined sharply, which illustrated that the whole system safety degree had raised greatly. The right-side column of Tab.1, minimum safety degree, showed that the reservoir groups could easily satisfy the requirement of flood control and make sure of handling capacity of next round flood.
Tab.1. The main comparison of two operation strategies

\begin{tabular}{|c|c|c|c|c|}
\hline \multirow[b]{2}{*}{ Reservoir } & \multicolumn{2}{|c|}{$\begin{array}{c}\text { Static-Piecewise } \\
\text { Linear }\end{array}$} & \multicolumn{2}{|c|}{ Dynamic-Piecewise Linear } \\
\hline & $\begin{array}{l}\text { Maximum } \\
\text { usage } \\
\text { percent } \\
(\%) \\
\end{array}$ & $\begin{array}{c}\text { Minimum } \\
\text { Safety } \\
\text { degree }\end{array}$ & $\begin{array}{c}\text { Maximum } \\
\text { usage } \\
\text { percent } \\
(\%) \\
\end{array}$ & $\begin{array}{c}\text { Minimum } \\
\text { Safety } \\
\text { degree }\end{array}$ \\
\hline Xiluodu & 82.67 & 0.57 & 96.65 & 0.16 \\
\hline Xiangjiaba & 64.58 & 0.75 & 70.57 & 0.69 \\
\hline Pubugou & 78.29 & 0.61 & 51.32 & 0.88 \\
\hline Zipingpu & 86.52 & 0.53 & 38.34 & 0.92 \\
\hline Tingzikou & 83.16 & 0.56 & 44.88 & 0.91 \\
\hline
\end{tabular}

The Tab.2 illustrated the accumulated usage of DFSC under conduction two strategies, which showed the reasonability allocation of each reservoir's flood storage capacity. Comparing with the static weight piecewise linear strategy, the dynamic one could guarantee the safety of all five reservoir by scientifically allocated the flood volume and ensure the safety of flood control section. Moreover, the dynamic weight piecewise linear strategy can make the process of flood routing more controllable and smooth for flood control section (Cuntan station). In conclusion, the dynamic one was more effective in ensuring the feasibility of the actual operation and improving the safety degree of each reservoir.

Tab.2. The accumulated usage of two operation strategies

\begin{tabular}{c|cc}
\hline Reservoir & $\begin{array}{c}\text { The accumulated } \\
\text { usage of Static- } \\
\text { Piecewise Linear } \\
(\%)\end{array}$ & $\begin{array}{c}\text { The accumulated usage of } \\
\text { Dynamic-Piecewise } \\
\text { Linear (\%) }\end{array}$ \\
\hline Xiluodu & $\begin{array}{c}3227.31 \\
\text { Xiangjiaba }\end{array}$ & $\begin{array}{c}547.19 \\
\text { Pubugou }\end{array}$ \\
\cline { 2 - 3 } Zipingpu & 2507.30 & 8674.51 \\
Tingzikou & 2047.80 & 1330.06 \\
\hline
\end{tabular}

\section{Conclusion and discussion}

This paper focused on quantitatively characterizing the safety degree of reservoirs and predictively considering flood forecast in flood control operation, and put forward novel operation strategy for flood control problem using optimization algorithm. The research result demonstrated: (1), Two operation strategies could effectively cut the flood peak and greatly completed the task of flood control and disaster reduction. (2), Transformed the predicted reservoir inflow into dynamic weight safety degree of each reservoir could excessively improve the flood control capability of reservoir groups. (3), The dynamic weight safety degree operation strategy can give full play to the role of each controlling reservoir in flood control operation and was more effective in ensuring the feasibility of the actual operation and improving the safety degree of each reservoir during flood season. 
On the premise of ensuring the minimum risk of flood control in the reservoir groups, selecting a better flood control operation strategy to optimize the operation mode of reservoir groups could effectively improve the comprehensive benefit of flood control and power generation efficiency. Furthermore, this achievement also has scientific effect on scheduling the flood risk of reservoir groups and may provide guidance for maximizing comprehensive benefits of the reservoir groups on flood control and hydropower generation.

\section{Acknowledgments}

This paper was financially supported by the National Key R\&D Program of China (Grant No. 2016YFC0402202) and the Fundamental Research Funds for the Central Universities (Grant No. 5003271021).

\section{References}

1. Yinghai Li, Qi Zhang, Xiaohua Dong, Jiali Guo. Review of Reservoirs Impounding Operation in Middle and Upper Yangtze River, [J] Journal of Water Resource Research, 2016, 5(5):452-459.

2. Ahmad, S., Simonovic, S.P. System dynamics modeling of reservoir operations for flood management, [J] Journal of Computing in Civil Engineering, 2000, 14(3):190-198

3. Lee, S., Kang, T, Lee, K.S. An operational model of a reservoir system simulation for real-time flood control in the Han River Basin, [J] Journal of Flood Risk Management, 2017, 10(4), 499-510

4. Becker, L., Yeh, W.W-G. Optimization of real time operation of a multiple-reservoir system, $[\mathrm{J}]$ Water Resources Research, 1974, 10 (6):1107-1112.

5. Jain, S.K., Yoganarasimhan, G.N., Seth, S.M. A Risk-based approach for Flood Control Operation of a Multipurpose Reservoir. [J] Journal of the American Water Resources Association, 1992, 28(6):1037-1043

6. R. Dittmann,F. Froehlich,R. Pohl,M. Ostrowski. Optimum multi-objective reservoir operation with emphasis on flood control and ecology, [J] Natural Hazards and Earth System Sciences \& Discussions, 2009, 9:1973-1980

7. Zhang S, Kang L, He X. Equal proportion flood retention strategy for the leading multireservoir system in upper Yangtze River, [C] International Conference on Water Resources and Environment, Wre. 2015.

8. Bao Li, Jianzhong Zhou, Shuo Ouyang. Application of Multi-Objective Particle Swarm Algorithm in Joint Flood Control Operation of Cascade Reservoirs, [J] Journal of Water Resource Research, 2012,1:44-50

9. Shuhai Zhang, Zhiwu Fan. Risk analysis for flood control operation of reservoir, [J] Journal of Hydraulic Engineering, 2004, 11:102-107
10. Dong, H., Ying, W., Zhang, J. A hybridizable discontinuous Galerkin method for elliptic interface problems in the formulation of boundary integral equations, [J] Journal of Computational and Applied Mathematics, 2018, 344:624-639

11. Chong-yu Xu, Lebing Gong, Tong Jiang, Deliang Chen, V.P.Singh. Analysis of spatial distribution and temporal trend of reference evapotranspiration and pan evaporation in Changjiang (Yangtze River) catchment, [J] Journal of Hydrology, 2006,327(1):81-93

12. Xia, B., Qiang, M., Chen, W. A benefit-sharing model for hydropower projects based on stakeholder input-output analysis: A case study of the Xiluodu Project in China, [J] Land Use policy, 2018, 73:341-352

13. Sun, Y., Teng, L., You, L. Study on flood resources utilization by Zipingpu key water-control project, [J] Journal of Hydroelectric Engineering, 2008,27(1):1-4

14. Qiu, Y., Meng, G., Wei, Y., Yao, K. An empirical analysis on influencing factors of the reservoir resettlement satisfaction, [J] Journal of Hydraulic Engineering, 2016, 47(5):663-673 